\title{
A importância dos novos marcadores do metabolismo ósseo
}

Observamos, nas últimas décadas, grande evolução no conhecimento da fisiologia do metabolismo ósseo e, conseqüentemente, significativa melhora no entendimento das doenças que afetam esse tecido.

A aperfeiçoada compreensão da fisiopatologia dos distúrbios mais relevantes facilitou a aplicação de recursos laboratoriais para o diagnóstico, o estabelecimento do prognóstico e o acompanhamento da resposta terapêutica da maioria deles.

Nesta edição do JBPML é apresentada uma revisão dos conhecimentos atuais dos métodos diagnósticos disponíveis para a detecção das doenças ósseas e suas peculiaridades: "Diagnóstico laboratorial e monitoramento das doenças osteometabólicas", do professor-doutor José Gilberto Henriques Vieira.

Entre as principais doenças osteometabólicas citadas se destacam a osteoporose, as hipercalcemias (incluindo o hiperparatireoidismo primário), o hiperparatireoidismo secundário (incluindo as deficiências de vitamina D) e a osteomalácia.

A osteoporose, cuja incidência aumenta com a idade, já é condição bastante comum e de alta morbimortalidade, especialmente entre mulheres na pós-menopausa, e a predisposição a fraturas é sua característica mais importante. Os dados da literatura evidenciam que, apesar de a densitometria óssea ser o método de escolha para o diagnóstico, a avaliação laboratorial é fundamental na definição e no diagnóstico das causas secundárias e no seguimento do tratamento.

O diagnóstico das hipercalcemias é fundamentalmente laboratorial, uma vez que as duas principais etiologias a serem investigadas são a hipercalcemia induzida por neoplasias e o hiperparatireoidismo primário, e o diagnóstico diferencial entre esses dois grupos é dependente dos recursos laboratoriais.

Outro grupo de doenças osteometabólicas é o hiperparatireoidismo secundário, seja por insuficiência renal crônica seja por deficiência de vitamina $D$, além de condições mais raras. Em todas elas o laboratório tem papel fundamental no diagnóstico etiológico e no seguimento terapêutico.

As metodologias mais recentemente disponíveis apresentam nítidas vantagens sobre os métodos clássicos de avaliação, como a dosagem do cálcio e da hidroxiprolina urinários e a dosagem da fosfatase alcalina. Os novos marcadores de formação óssea incluem a fosfatase alcalina óssea específica, a osteocalcina e o propeptídeo de procolágeno tipo I (PNPI); os de reabsorção compreendem a medida dos interligadores de colágeno piridinolinas, deoxipiridinolinas, interligadores C e N terminais. Observamos, assim, a importância do laboratório clínico atualizado, renovando recursos para prestar melhor contribuição ao atendimento à saúde.

Adicionalmente, este número traz informações atuais sobre a proteína C-reativa ultra-sensível (PCRus) como marcador de doença arterial coronariana; a importância do estudo dos parâmetros de coagulação no paciente com infarto agudo do miocárdio e, na linha da identificação de riscos da doença aterosclerótica, um extenso trabalho relativo ao perfil lipídico em crianças.

De igual importância são os dados apresentados no trabalho do professor-doutor Luiz Cláudio Santos Thuler sobre o perfil dos laboratórios de citopatologia operantes no Sistema Único de Saúde (SUS).

Como a biologia molecular tem acrescentado recursos de elevada utilidade diagnóstica, a análise crítica dos métodos de extração de DNA de material parafinado para amplificação por PCR, como a encontrada no trabalho do professor Glauco Issami Miyara, é altamente desejável e atual.

Boa leitura. 